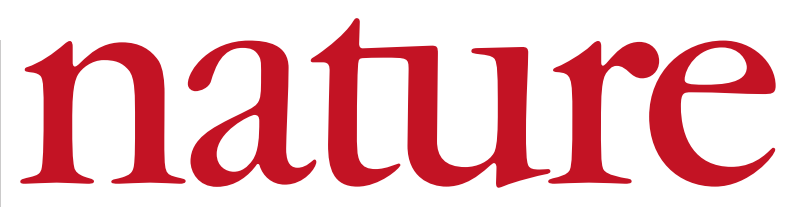

24 February 2005 Volume 433 Issue no 7028

\title{
Making sense of the world
}

The Earth and our effects on it require monitoring and analysis worthy of their complexity and importance. Now is the time to bring global observation into the twenty-first century.

L ast week, ministers from some 60 nations gathered in Brussels to create an integrated Earth observation system, the Global Earth Observation System of Systems (GEOSS). December's tsunami in the Indian Ocean has catapulted GEOSS from relative obscurity to high on the international political agenda. This was clear from the presence of Carlos Gutierrez, the US commerce secretary, on his first overseas visit since being sworn in on 7 February, as well as science ministers from around the planet (see page 789).

The tsunami disaster highlighted the power of Earth observation data, but it has also thrown a harsh spotlight on the patchiness and rudimentary nature of current systems for understanding complex Earth systems and applying that knowledge to agriculture, management of water resources, early-warning systems for natural disasters, and more.

Take ocean currents, which affect climate by shifting large volumes of warm and cold water around the planet. A United Nations body set up in 1991 to observe, model and analyse the world's oceans, the Global Ocean Observing System (GOOS), has been chronically underfunded and has installed barely half of the monitoring instruments envisaged. Similar inadequacies undermine the Global Climate Observing System (GCOS) set up in 1992.

Speak to people working in global networks in almost any area of Earth observation and the message is the same: behind the stunning images and model simulations of planet Earth lies a much more disconnected picture. Countries and agencies tend to pursue their own agendas, resulting in duplication and a lack of sharing, and coverage is disproportionately concentrated in rich countries. Data come in overly diverse formats and units, making them difficult to use. Researchers, particularly those outside the Earth observation community, complain of costs, delays and other obstacles to getting the sorts of data they need.

\section{Sooner than you think}

\section{Nature's back-page fiction is good for you.}

W hat does the next half-century have in store? The record of the past fifty years shows that almost anything could happen. In 1955, the structure of DNA had been known only two years, and the complete sequence of the human genome wasn't even a distant prospect. Indeed, there were fewer than half as many humans as there are now. Roomfuls of vacuum-tube equipment were needed for computing power dwarfed by objects we now carry in our pockets. There were no cell-phones, no integrated circuits and almost no television. Antibiotics and transistors were novelties, the cold war a reality, and quarks existed only in James Joyce's Finnegans Wake. Space exploration was a dream yet to be realized.

In the same era, a generation inspired by the possibilities of science had taken an old 'westerns-in-space' formula and begun to forge a new kind of literature that asked serious questions about how technological change might affect the way we think about ourselves and other people. This was the golden age of science fiction. The 1950s
Today's climate observation system is cobbled together from data from research satellites, weather satellites, atmospheric sounders and whatever ground-based observation stations scientists can get their hands on, rather than being tailored to monitoring and understanding climate change and variability. Research satellites last only a few years and are not replaced immediately, if at all. But for reliable climate-change monitoring over decades, it is essential, for example, to launch a follow-up satellite while its predecessor is still operating, so instruments on both can be cross-calibrated.

GEOSS is key to addressing such shortcomings. But researchers and other user communities should ensure that their needs are heard. Better international coordination promises to make better use of the billions of dollars that are already spent on Earth observation. But there is a limit to the benefits that can be squeezed out of coordinating and networking activities, when support for the basic scientific activity of collecting critical observations is neglected. Ultimately, GEOSS must make the case for, and oversee, an upgrading of systems such as GCOS and GOOS.

An optimistic view is that the political momentum to treat Earth observation more like global 'big science' facilities will translate into a better understanding and support of key scientific needs. The decision to house GEOSS within the World Meteorological Organization may bode well in this respect, as this Geneva-based UN agency has a good track record in mounting international operational weather systems.

But as the tsunami fades from memory, there is also a risk that the new-found political awareness will also subside. As GEOSS charts out what exactly it will do, scientists should actively engage with current political will by pressing home compelling arguments as to how better understanding of the spatial and temporal variability of the wide range of Earth-system parameters will result in progress.

saw the publication of - to pick a few choice pebbles from the shore - Robert Heinlein's The Man Who Sold the Moon, Isaac Asimov's Foundation, Arthur C. Clarke's Childhood's End, Alfred Bester's The Stars My Destination and Walter Miller's A Canticle for Leibowitz.

In 1999 and 2000, Nature ran Futures, a series of science-fiction vignettes on what the coming millennium had to offer. Publishers know that, job-seekers apart, readers' attention wanes as they penetrate further into a magazine. So it may only be our most astute or compulsive enthusiasts who have noticed over the past few weeks that Futures has returned, on the back page of each issue.

Nature is proud to present Futures as a forum for the best new science-fiction writing, and the pieces - commissioned from wellestablished and novice writers alike - explore some of the themes that might challenge us in the next half-century or so. Prepare to be amused, stimulated, even outraged, but know this: the future is sooner than you think. 